Departamento de Ciências Agrărias e Tecnológicas, Universidade Federal do Tocantins (UFT), Rua Badejōs, 69-72. Zona Rural, CEP 77402-970, Gurupi, TO, Brasil

*autor correspondente 凶 fidelisrr@mail.uft.edu.br

\title{
Eficiência de genótipos de arroz no uso de nitrogênio em solos de terras altas
}

\author{
Efficiency of rice genotypes in the use nitrogen in upland soils
}

Raphael Campestrini' ${ }^{1}$, Rogel Galvão Prates ${ }^{1}$, Sérgio Alves de Sousa' ${ }^{1}$, Taynar Coelho de Oliveira', Joedna Silva', Rodrigo Ribeiro Fidelis ${ }^{1 *}$

RESUMO: O arroz (Oryza sativa L.) é considerado um dos mais importantes grãos em termos de valor econômico, visto que é cultivado e consumido em todo o mundo. Essa cultura destaca-se por ser extremamente exigente em nutrientes, principalmente o nitrogênio, fator limitante da produção. Em função disso, a seleção de genótipos com maior eficiência na utilização de nitrogênio contribui para aumentar a produtividade de grãos da cultura do arroz, além de evitar possíveis problemas ambientais advindos da poluição por este nutriente, pela lixiviação de nitrato ou perdas por volatilização. O objetivo deste trabalho foi avaliar a existência de diferenças entre genótipos de arroz quanto à eficiência no uso de nitrogênio em solos de terras altas do sul do Estado do Tocantins. As cultivares utilizadas foram: BRS - Sertaneja, BRS - Primavera, BRS - Bonança, BRSMG - Conai, BRS - Aroma, BRS - Monarca, BRS - Pepita, BRSGO - Bolinha, Japonês e Serra Dourada. A avaliação das cultivares foi realizada em dois experimentos para simular ambientes com baixo e alto nível de nitrogênio, sendo utilizadas doses de 20 e 120 $\mathrm{kg} \mathrm{ha}^{-1}$ de $\mathrm{N}$, respectivamente. As características avaliadas foram: dias para florescimento, altura das plantas, número de panículas por metro quadrado, massa de cem grãos, produtividade de grãos e índices de clorofilas. Com isso, conclui-se que: (i) a cultivar Serra Dourada foi considerada eficiente e responsiva à adubação de $\mathrm{N}$, e (ii) o ambiente de alto nitrogênio resultou em maiores alturas de plantas e maior teor clorofila $a$.

PALAVRAS-CHAVE: Oryza sativa, estresse mineral, produtividade.
ABSTRACT: Rice (Oryza sativa L.) is considered a very important grain in terms of economic value because it is grown and consumed worldwide. This culture stands out for being extremely demanding for nutrients, mainly nitrogen, which becomes a limiting factor to production. As a result, selection of genotypes with more efficient use of nitrogen contributes to increase grain yield of rice, in addition to avoiding possible environmental problems arising from this nutrient pollution, nitrate leaching, or volatilization losses. The aim of this study was to evaluate the existence of differences between rice genotypes regarding nitrogen use efficiency in soils of the southern uplands of Tocantins state. The following rice cultivars were used in this study: BRS - Sertaneja, BRS - Primavera, BRS - Bonança, BRSMG - Conai, BRS - Aroma, BRS - Monarca, BRS - Pepita, BRSGO - Bolinha, Japonês, and Serra Dourada. Cultivar evaluation was performed in two experiments to simulate environments with low and high nitrogen levels using doses of 20 and $120 \mathrm{~kg} \mathrm{ha}^{-1} \mathrm{~N}$. The characteristics evaluated were as follows: number of days to heading, plant height, number of panicles per $m^{2}$, one-hundred grains mass, grain yield, and chlorophyll indexes. Thus, it is possible to conclude that (i) cultivar Serra Dourada was considered efficient and responsive to $N$ fertilization; (ii) nitrogen-rich environment resulted in greater plant height and content of chlorophyll $a$.

KEYWORDS: Oryza sativa, mineral stress, yield.

\section{Introdução}

$\mathrm{O}$ arroz (Oryza sativa L.) é considerado o produto de maior importância econômica em muitos países em desenvolvimento. Com o aumento crescente de seu consumo, influenciado pelo crescimento populacional, impõe-se ao setor produtivo a busca de novas técnicas que possam aumentar a produção. Cultivado e consumido em todos os continentes, o arroz se 
destaca pela expressividade na produção e na área de cultivo, desempenhando papel estratégico tanto no aspecto econômico quanto social (FAGERIA; BALIGAR; JONES, 1997).

No Brasil, de acordo com dados da Conab (COMPANHIA..., 2012), a área cultivada com arroz na safra 2011/12 está em torno de 2.470,8 mil hectares, $12,4 \%$ menor do que a área da safra anterior. $\mathrm{O}$ arroz de sequeiro é cultivado em 1,1 milhão de hectares, representando $43,24 \%$ da área nacional.

O Estado do Tocantins apresentou uma área de 120,1 mil hectares para a safra de arroz 2011/2012, com uma produção de 442,7 mil toneladas e uma produtividade média de $3.686 \mathrm{~kg} \mathrm{ha}^{-1}$ (COMPANHIA..., 2012).

$\mathrm{O}$ nitrogênio $(\mathrm{N})$ é essencial para as plantas, pois é constituinte de moléculas, como clorofilas, citocromos, enzimas e coenzimas. Também participa na formação da panícula e dos grãos de arroz (BARBOSA FILHO, 1987). A planta de arroz é extremamente exigente em nutrientes, sendo necessário que estes estejam presentes e prontamente disponíveis nos momentos de demanda, para não limitar a produtividade. Depois do potássio, o nitrogênio é o nutriente que a planta de arroz mais acumula, influenciando diretamente em sua produtividade. $\mathrm{O} \mathrm{N}$ contribui para o aumento da área foliar da planta que, por sua vez, aumenta a eficiência de intercepção da radiação solar e da taxa fotossintética, consequentemente, melhora-se a produtividade de grãos (FAGERIA; SLATON; BALIGAR, 2003).

O uso racional da adubação nitrogenada é de extrema importância não somente para aumentar a eficiência de recuperação, mas também para elevar a produtividade da cultura e diminuir o custo de produção e os riscos de poluição ambiental (FAGERIA; STONE, 2003). Plantas com alta eficiência no uso de $\mathrm{N}$ são desejáveis para as cultivares de arroz usadas na agricultura de baixos insumos.

Estudos mostram a existência de diferenças genotípicas na eficiência de absorção de nitrogênio em arroz (FERRAZ JUNIOR et al., 1997; KISCHEL et al., 2011). Ferraz Junior et al. (1997) observaram uma alta eficiência de absorção de $\mathrm{N}$ para produção de grãos em cultivares melhoradas, em comparação a outras cultivares de arroz que são conhecidas como tradicionais. Kischel et al. (2011) constataram a diferença quanto à eficiência de absorção de nitrogênio em genótipos de arroz irrigado cultivados em várzea.

O objetivo deste trabalho foi avaliar diferenças entre genótipos de arroz quanto à eficiência no uso de nitrogênio em solos de terras altas do sul do Estado do Tocantins.

\section{Material e Métodos}

A avaliação das cultivares foi realizada em dois experimentos contrastantes em relação a doses de nitrogênio. Um experimento representou o ambiente de baixo nível de $\mathrm{N}\left(20 \mathrm{~kg} \mathrm{ha}^{-1}\right) \mathrm{e}$ outro, o ambiente de alto nível de $\mathrm{N}\left(120 \mathrm{~kg} \mathrm{ha}^{-1}\right)$, em terras altas no município de Gurupi-TO, no campo experimental da Universidade Federal do Tocantins, localizado a uma altitude de $285 \mathrm{~m}$, latitude $11^{\circ} 44^{\prime} 48^{\prime \prime} \mathrm{S}$ e longitude $49^{\circ} 03^{\prime} 12^{\prime \prime} \mathrm{O}$, safra 2011/12.
Os dois experimentos foram conduzidos em delineamento experimental de blocos casualizados, com quatro repetições, em que cada parcela experimental foi constituída por quatro linhas de 5,0 m de comprimento, espaçadas de $45 \mathrm{~cm} \mathrm{e}$ 60 sementes por metro linear. Para a área útil, foram utilizadas as duas linhas centrais com 4,0 $\mathrm{m}$ de comprimento, desprezando $50 \mathrm{~cm}$ das extremidades.

Para a realização dos estudos, foram utilizadas as cultivares mais adaptadas ao ambiente de terras altas no Estado: BRS - Sertaneja, BRS - Primavera, BRS - Bonança, BRSMG - Conai, BRS - Aroma, BRS - Monarca, BRS - Pepita, BRSGO - Bolinha, Japonês e Serra Dourada.

Foi realizada análise química e física do solo na camada de $0-20 \mathrm{~cm}$, coletado antes da instalação do experimento, apresentaram-se os seguintes resultados para o ambiente de baixo $\mathrm{N}: \mathrm{Ca}=1,02 \mathrm{cmol}_{\mathrm{c}} \mathrm{dm}^{-3} ; \mathrm{Mg}=0,55 \mathrm{cmol}_{\mathrm{c}} \mathrm{dm}^{-3}$; $\mathrm{H}+\mathrm{Al}=1,02 \mathrm{cmol}_{\mathrm{c}} \mathrm{dm}^{-3} ; \mathrm{K}=0,08 \mathrm{cmol}_{\mathrm{c}} \mathrm{dm}^{-3}$; $\mathrm{SB}=1,63 \mathrm{cmol}_{\mathrm{c}} \mathrm{dm}^{-3} ; \mathrm{P}\left(\mathrm{Melich}^{-1}\right)=11,12 \mathrm{mg} \mathrm{dm}^{-3} ; \mathrm{V}=61,4 \%$; M.O $\left(\mathrm{g} \mathrm{dm}^{-3}\right)=13,32 ; \mathrm{pH} \mathrm{em} \mathrm{H} \mathrm{H}_{2} \mathrm{O}=6,3$; areia $\left(542,4 \mathrm{~g} \mathrm{~kg}^{-1}\right)$; silte $\left(54,9 \mathrm{~g} \mathrm{~kg}^{-1}\right)$, e argila $\left(402,7 \mathrm{~g} \mathrm{~kg}^{-1}\right)$. No experimento de alto $\mathrm{N}$, obtiveram-se os seguintes resultados: $\mathrm{Ca}=0,82 \mathrm{cmol}_{c} \mathrm{dm}^{-3}$; $\mathrm{Mg}=0,62 \mathrm{cmol}_{\mathrm{c}} \mathrm{dm}^{-3} ; \mathrm{H}+\mathrm{Al}=0,23 \mathrm{cmol}_{\mathrm{c}} \mathrm{dm}^{-3} ;$ $\mathrm{K}=0,08 \mathrm{cmol}_{\mathrm{c}} \mathrm{dm}^{-3} ; \mathrm{SB}=1,5 \mathrm{cmol}_{\mathrm{c}} \mathrm{dm}^{-3}$; $\mathrm{P}\left(\mathrm{Melich}^{-1}\right)=9,99 \mathrm{mg} \mathrm{dm}^{-3} ; \mathrm{V}=86,67 \% ; \mathrm{M} . \mathrm{O}\left(\mathrm{g} \mathrm{dm}^{-3}\right)=11,41$; $\mathrm{pH}$ em $\mathrm{H}_{2} \mathrm{O}=6,15$; areia $\left(542,4 \mathrm{~g} \mathrm{~kg}^{-1}\right)$; silte $\left(54,9 \mathrm{~g} \mathrm{~kg}^{-1}\right)$, e argila $\left(402,7 \mathrm{~g} \mathrm{~kg}^{-1}\right)$.

O preparo do solo foi realizado de forma convencional, com uma gradagem pesada seguida de grade niveladora. A semeadura foi realizada manualmente no dia 10 de dezembro de 2011. A adubação de semeadura foi realizada no sulco de plantio, com base nos resultados da análise química e física do solo. Em ambos os ambientes, foi utilizado o adubo químico formulado NPK 5-25-15, aplicando-se $360 \mathrm{~kg} \mathrm{ha}^{-1}$. A adubação de cobertura para o ambiente de alto $\mathrm{N}$ foi dividida em duas etapas, sendo na primeira aplicados $52 \mathrm{~kg} \mathrm{ha}^{-1} \mathrm{de} \mathrm{N}$ na forma de ureia, na ocasião do perfilhamento efetivo, e na outra, foram aplicados $50 \mathrm{~kg} \mathrm{ha}^{-1}$ de $\mathrm{N}$ na forma de ureia, na fase de diferenciação do primórdio floral.

Os tratos culturais foram efetuados mediante aplicação de herbicida pré-emergente para o controle de plantas daninhas com OXIFLUORFEM, na dosagem de $85 \mathrm{~mL} \mathrm{ha}^{-1}$ do produto comercial Goal BR (240 g i.a./ha). Antes da adubação de cobertura, foi feita uma aplicação de pós-emergente utilizando Bentazon, na dosagem de $160 \mathrm{~mL} \mathrm{ha}^{-1}$ do produto comercial Basagran (600 g i.a./ha). Para complementar os tratos culturais, foi realizada uma capina manual logo após o florescimento. Não houve a necessidade da aplicação de inseticidas e fungicidas durante a condução do experimento.

Foram avaliadas as seguintes variáveis: número de dias para o florescimento (DF) - dias para a emissão de 50\% das panículas, a partir da data de plantio; altura de plantas (AP) - medida da superfície do solo até o ápice da panícula do colmo central, excluindo a arista, quando presente; número de panículas por metro quadrado (NP) - contando-se as panículas em $1 \mathrm{~m}^{2}$ da área útil da parcela; produtividade de grãos (PG) - produção de grãos limpos com 13\% de umidade, em $\mathrm{kg} \mathrm{ha}^{-1}$; massa de cem grãos (MCG) - massa de uma amostra 
de cem grãos sadios por parcela; índice de clorofila $a(\mathrm{Cl}$ a); índice de clorofila $b(\mathrm{Cl}$ b); relação entre índices de clorofila $a$ e $b$, obtida pela divisão desses índices $(\mathrm{Cl} a / \mathrm{Cl} b)$; e índice de clorofila total ( $\mathrm{Cl}$ Total). As leituras de clorofila foram feitas no terço médio da planta, na parte central do limbo foliar, em dez plantas de cada parcela, antes do florescimento. Essas leituras foram realizadas com auxílio de um clorofilômetro da marca comercial ClorofiLOG ${ }^{\circledR}$ modelo CFL 1030, produzido pela Falker Automação Agrícola. Os valores dos índices de clorofila são representados pelo Índice de Clorofila Falker - ICF (FALKER..., 2008).

Os dados experimentais foram submetidos à análise individual e conjunta de variância, com aplicação do teste F. A análise conjunta foi aplicada sob condições de homogeneidade das variâncias residuais. Para as comparações entre as médias de tratamentos, foi utilizado o teste Tukey, e para as comparações entre cultivares, foi utilizado o teste Scott-knott, ambos a 5\% de probabilidade de resíduo, utilizando-se o aplicativo computacional SISVAR (FERREIRA, 2011).

Para diferenciar as cultivares, foi utilizada a metodologia proposta por Fageria e Kluthcouski (1980), a qual permite a classificação das cultivares quanto à eficiência no uso e resposta à aplicação de nitrogênio (eficiência e resposta - ER). Segundo este indicador, a eficiência na utilização do nutriente é definida pela média de produtividade de grãos em baixo nível de nutriente e a resposta à utilização do nutriente é obtida pela diferença entre a produtividade de grãos nos dois níveis dividida pela diferença entre as doses, conforme a seguinte equação:

$$
\mathrm{IR}=(\mathrm{AN}-\mathrm{BN}) / \mathrm{DEN}
$$

Em que:

IR= Índice de Resposta;

AN = Produção com alto nível de nitrogênio;

$\mathrm{BN}=$ Produção com baixo nível de nitrogênio;

DEN $=$ Diferença entre as doses de $\mathrm{N}\left(\mathrm{kg} \mathrm{ha}^{-1}\right)$.

A classificação das cultivares foi representada no plano cartesiano, da seguinte forma: no eixo das abscissas (x), encontra-se a eficiência na utilização do nitrogênio, e no eixo das ordenadas (y), o índice de resposta à sua utilização. O ponto de origem dos eixos é a eficiência média e a resposta média das cultivares. No primeiro quadrante, são representadas as cultivares eficientes e responsivas (ER); no segundo, as não eficientes e responsivas (NER); no terceiro, as não eficientes e não responsivas (NENR), e no quarto, as eficientes e não responsivas (ENR).

\section{Resultados e Discussão}

As análises de variância mostraram que, apenas para a característica índice de clorofila $a$, não houve significância da interação, ou seja, os ambientes não influenciaram de forma diferenciada na expressão das cultivares, devendo, então, os fatores serem estudados isoladamente. Porém, para número de dias para florescimento, altura de plantas, número de panículas, massa de cem grãos, produtividade de grãos, índice de clorofila $b$, relação entre índice de clorofila $a$ e $b$, e índice de clorofila total, houve significância da interação, significando que as cultivares são influenciadas de forma diferenciada pelo ambiente, sendo, portanto, necessário o desdobramento dos fatores. As análises de variância mostraram ainda diferença significativa entre as cultivares e os ambientes para todas as características avaliadas.

Observam-se, para a maioria das características, baixos coeficientes de variação (Tabelas 1 e 2), que variam entre 0,9 e 16,1\%, indicando boa precisão experimental, mesmo sendo cultivados sob condições de estresse. Entretanto, as características massa de cem grãos e produtividade de grãos apresentaram elevados coeficientes de variação - 22,57\% e 46,31\% (Tabela 3), respectivamente. De acordo com Blum (1988), esses elevados coeficientes de variação não são considerados necessariamente como inadequados, visto que os ensaios foram realizados sob condições de estresse. Estudos realizados em ambientes sob condições de estresse mineral também apresentaram elevados coeficientes de variação, como o realizado por Fidelis, Miranda e Faluba (2010), com a cultura do milho, e Cancellier et al. (2011), com a cultura do arroz.

Quanto ao número de dias para florescimento (Tabela 1), observa-se que a cultivar BRSGO - Bolinha apresentou florescimento mais tardio nos dois ambientes, sem diferir da cultivar Japonês no ambiente de alto $\mathrm{N}$. A cultivar que se apresentou mais precoce, independentemente do ambiente, foi BRSMG - Conai, com aproximadamente 66 dias para florescimento, valor bem abaixo dos 82 DAE (dias após emergência), encontrado por Silva et al. (2009) para a mesma cultivar sob condição de sequeiro, na safra 2005/2006. De acordo com Streck et al. (2006), muitos genótipos de arroz sofrem influência da temperatura e do fotoperíodo, por ser uma planta de dias curtos, esses fatores acabam influenciando na duração do ciclo de desenvolvimento. Assim, a temperatura e o fotoperíodo podem explicar a diferença no florescimento da cultivar BRSMG - Conai, quando cultivada no município de Gurupi-TO, em relação a Cassilândia-MS. Todas as cultivares, excetuando-se BRS - Primavera, tiveram o ciclo aumentado quando cultivadas em condições ideais de nitrogênio. Essa antecipação da fase reprodutiva da planta em virtude do estresse nutricional já foi evidenciada por Taiz e Zeiger (2004), reportando que o trajeto floral, bem como as demais etapas do desenvolvimento reprodutivo, são favorecidos por um balanço carbono/nitrogênio quantitativamente favorável ao primeiro assimilado e, em algumas espécies, o nitrato está relacionado à inibição floral, fazendo com que as menores adubações nitrogenadas antecipem o florescimento das plantas.

Para a característica altura de plantas (Tabela 1), foi observado que o ambiente de alto $\mathrm{N}$ resultou em maiores médias para todas as cultivares, quando comparado ao ambiente de baixo N. Resultados semelhantes foram encontrados por Kischel et al. (2011) em ambiente de várzea irrigada. No ambiente de alto $\mathrm{N}$, a maior estatura observada foi da cultivar BRSGO - Bolinha $(107,3 \mathrm{~cm})$ e as menores médias para as cultivares BRS - Sertaneja e BRSMG - Conai (abaixo de $80 \mathrm{~cm}$ ). Para o ambiente de baixo N, a maior média também foi obtida pela cultivar BRSGO - Bolinha $(93,5 \mathrm{~cm})$, não 
Tabela 1. Médias das características número de dias para florescimento (DF), altura de plantas (AP) e número de panículas por m² (NP), sob alta e baixa dose de $\mathrm{N}$ (120 kg ha ${ }^{-1}$ e $20 \mathrm{~kg} \mathrm{ha}^{-1}$, respectivamente), para cultivares de arroz de terras altas, na região sul do Estado do Tocantins, Gurupi, Tocantins, safra $2011 / 2012$.

\begin{tabular}{|c|c|c|c|c|c|c|c|c|c|}
\hline \multirow[b]{2}{*}{ Cultivar } & \multicolumn{3}{|c|}{ DF (dias) } & \multicolumn{3}{|c|}{$\mathbf{A P}(\mathbf{c m})$} & \multicolumn{3}{|c|}{ NP (unidade) } \\
\hline & $\begin{array}{c}\text { Alto } \\
\mathbf{N}\end{array}$ & $\begin{array}{c}\text { Baixo } \\
\mathbf{N}\end{array}$ & Média & $\begin{array}{c}\text { Alto } \\
\mathbf{N}\end{array}$ & $\begin{array}{c}\text { Baixo } \\
\mathbf{N}\end{array}$ & Média & $\begin{array}{c}\text { Alto } \\
\mathbf{N}\end{array}$ & $\begin{array}{c}\text { Baixo } \\
\mathbf{N}\end{array}$ & Média \\
\hline BRS-Sertaneja & $86,0 \mathrm{bA}$ & $84,0 \mathrm{cB}$ & 85,0 & $67,5 \mathrm{fA}$ & $61,6 \mathrm{~dB}$ & 64,5 & $90,1 \mathrm{bA}$ & $79,1 \mathrm{aA}$ & 84,6 \\
\hline BRS-Primavera & $73,5 \mathrm{eA}$ & $73,3 \mathrm{gA}$ & 73,4 & $93,9 \mathrm{cA}$ & $80,3 \mathrm{bB}$ & 87,1 & $68,0 \mathrm{cA}$ & $74,5 \mathrm{aA}$ & 71,3 \\
\hline BRS-Bonança & $78,5 \mathrm{dA}$ & $77,0 \mathrm{eB}$ & 77,8 & $82,7 \mathrm{dA}$ & $75,6 \mathrm{bB}$ & 79,2 & $76,4 \mathrm{cA}$ & $67,1 \mathrm{aA}$ & 71,8 \\
\hline BRSMG-Conai & $67,0 \mathrm{gA}$ & $64,5 \mathrm{jB}$ & 65,8 & $73,3 \mathrm{eA}$ & $66,6 \mathrm{cB}$ & 70,0 & $89,8 \mathrm{bA}$ & $66,6 \mathrm{aB}$ & 78,2 \\
\hline BRS-Aroma & $77,5 \mathrm{dA}$ & $75,0 \mathrm{fB}$ & 76,3 & $89,3 \mathrm{cA}$ & $74,0 \mathrm{bB}$ & 81,6 & $86,5 \mathrm{bA}$ & $75,8 \mathrm{aA}$ & 81,1 \\
\hline BRS-Monarca & $82,0 \mathrm{cA}$ & $77,8 \mathrm{~dB}$ & 79,9 & $83,8 \mathrm{dA}$ & $77,3 \mathrm{bB}$ & 80,5 & $75,4 \mathrm{cA}$ & $71,0 \mathrm{aA}$ & 73,2 \\
\hline BRS-Pepita & $69,8 \mathrm{fA}$ & $66,5 \mathrm{iB}$ & 68,1 & $94,1 \mathrm{cA}$ & $73,8 \mathrm{bB}$ & 84,0 & $90,3 \mathrm{bA}$ & $54,6 \mathrm{bB}$ & 72,4 \\
\hline BRSGO-Bolinha & $96,3 \mathrm{aA}$ & $94,5 \mathrm{aB}$ & 95,4 & $107,3 \mathrm{aA}$ & $93,5 \mathrm{aB}$ & 100,4 & $73,1 \mathrm{cA}$ & $55,3 \mathrm{bB}$ & 64,2 \\
\hline Japonês & $96,3 \mathrm{aA}$ & $94,0 \mathrm{bB}$ & 95,1 & $100,1 \mathrm{bA}$ & $88,8 \mathrm{aB}$ & 94,4 & $68,5 \mathrm{cA}$ & $47,8 \mathrm{bB}$ & 58,1 \\
\hline Serra Dourada & $69,8 \mathrm{fA}$ & $68,0 \mathrm{hB}$ & 68,9 & $83,9 \mathrm{dA}$ & $69,8 \mathrm{cB}$ & 76,8 & $109,6 \mathrm{aA}$ & $69,0 \mathrm{aB}$ & 89,3 \\
\hline Média Geral & 79,7 & 77,5 & - & 87,6 & 76,1 & - & 82,8 & 66,1 & - \\
\hline $\mathrm{CV}(\%)$ & \multicolumn{2}{|c|}{0,93} & & \multicolumn{2}{|c|}{4,53} & & \multicolumn{2}{|c|}{16,06} & \\
\hline
\end{tabular}

Médias seguidas de mesma letra minúscula nas colunas não diferem entre si pelo teste Scott - knott, e de mesma letra maiúscula nas linhas não diferem entre si pelo teste Tukey, a $5 \%$ de probabilidade.

Tabela 2. Média das características clorofila $a(C l a)$ e clorofila $b(C l b)$, sob alta e baixa dose de $\mathrm{N}\left(120 \mathrm{~kg} \mathrm{ha}^{-1}\right.$ e $20 \mathrm{~kg}$ ha ${ }^{-1}$, respectivamente), para cultivares de arroz de terras altas na região sul do Estado do Tocantins, Gurupi, Tocantins, safra 2011/2012.

\begin{tabular}{|c|c|c|c|c|c|c|}
\hline \multirow{2}{*}{ Cultivar } & \multicolumn{3}{|c|}{ Cla $(\mathrm{ICF})$} & \multicolumn{3}{|c|}{$C l b$ (ICF) } \\
\hline & Alto N & Baixo N & Média & Alto $\mathbf{N}$ & Baixo N & Média \\
\hline BRS-Sertaneja & 32,59 & 31,49 & $32,04 \mathrm{c}$ & $9,30 \mathrm{dA}$ & $9,43 \mathrm{bA}$ & 9,36 \\
\hline BRS-Primavera & 38,12 & 35,86 & 36,99 a & $15,52 \mathrm{aA}$ & $11,62 \mathrm{aB}$ & 13,56 \\
\hline BRS-Bonança & 38,41 & 36,10 & $37,25 \mathrm{a}$ & $15,61 \mathrm{aA}$ & $12,55 \mathrm{aB}$ & 14,08 \\
\hline BRSMG-Conai & 36,5 & 34,84 & $35,67 \mathrm{~b}$ & $13,58 \mathrm{bA}$ & $10,71 \mathrm{bB}$ & 12,15 \\
\hline BRS-Aroma & 35,57 & 32,93 & $34,25 \mathrm{~b}$ & $12,46 \mathrm{cA}$ & $9,43 \mathrm{bB}$ & 10,95 \\
\hline BRS-Monarca & 36,38 & 34,05 & $35,22 \mathrm{~b}$ & $12,96 \mathrm{cA}$ & 9,64 bB & 11,3 \\
\hline BRS-Pepita & 37,77 & 34,16 & $35,96 \mathrm{~b}$ & $14,16 \mathrm{bA}$ & $9,84 \mathrm{bB}$ & 12,0 \\
\hline BRSGO-Bolinha & 36,03 & 34,02 & $35,02 \mathrm{~b}$ & $11,82 \mathrm{cA}$ & $11,01 \mathrm{aA}$ & 11,42 \\
\hline Japonês & 35,10 & 34,92 & $35,01 \mathrm{~b}$ & $11,17 \mathrm{cA}$ & $12,12 \mathrm{aA}$ & 11,64 \\
\hline Serra Dourada & 35,51 & 34,73 & $35,12 \mathrm{~b}$ & $12,06 \mathrm{cA}$ & $9,80 \mathrm{bB}$ & 10,93 \\
\hline Média & $36,20 \mathrm{~A}$ & $34,31 \mathrm{~B}$ & - & 12,86 & 10,62 & - \\
\hline $\mathrm{CV}(\%)$ & \multicolumn{2}{|c|}{3,66} & \multicolumn{4}{|c|}{8,5} \\
\hline
\end{tabular}

Médias seguidas de mesma letra minúscula nas colunas não diferem entre si pelo teste Scott - knott, e de mesma letra maiúscula nas linhas não diferem entre si pelo teste Tukey, a $5 \%$ de probabilidade.

diferindo significativamente da cultivar Japonês $(88,8 \mathrm{~cm})$. De acordo com Castro Neto (2009), as alturas em torno de 0,90 m são consideradas satisfatórias para o cultivo mecanizado na região, diversamente, as alturas acima de 1,00 m fazem com que as cultivares tenham maior facilidade ao acamamento, ocasionando em perdas aos orizicultores.

A cultivar Serra Dourada mostrou maior número de panículas por metro quadrado (Tabela 1), independentemente do ambiente, porém, sem diferir significativamente dos cultivares BRS - Sertaneja, BRS - Aroma, BRSMG - Conai, BRS - Monarca, BRS - Bonança e BRS - Primavera, no ambiente de baixo N. A redução na dose de nitrogênio proporcionou a diminuição do número de panículas por metro quadrado, com exceção da cultivar BRS - Primavera, que aumentou o número de panículas com a redução da dose de nitrogênio. De acordo com Fageria, Baligar e Clark (2006), o número de panículas é considerado uma característica da cultivar, contudo, essa característica pode ser aumentada com a aplicação de dose adequada de $\mathrm{N}$.

Quanto ao índice de clorofila $a$ (Tabela 2), nota-se superioridade das cultivares BRS - Bonança e BRS - Primavera. Observa-se ainda que o ambiente de alto $\mathrm{N}$ resulta em maiores 
médias de clorofila $a$. De acordo com Silva et al. (2008), há uma relação direta entre as leituras do clorofilômetro e o teor de nitrogênio nas folhas de arroz irrigado. Esses autores relataram que as maiores leituras não refletem diretamente em maiores produtividades.

Analisando-se os dados apresentados nas Tabelas 2 e 4, nota-se que as cultivares BRS - Bonança e BRS - Primavera fazem parte do grupo estatístico que apresentou os maiores índices de clorofila $a, b$ e total, independentemente do ambiente. Os teores obtidos de clorofila $b$ foram altos, o que resulta em uma baixa razão $a / b$, o que pode ser evidenciado analisando as relações das cultivares BRS - Bonança e BRS - Primavera.
Quanto à característica índice de clorofila total (Tabela 4), as cultivares que compuseram o grupo estatístico de maior média, independentemente do ambiente, foram BRS - Bonança e BRS - Primavera, com índices superiores a 47 ICF. De acordo com Barbieri Junior (2009), o índice de clorofila nas folhas das plantas apresenta uma alta correlação com o teor de $\mathrm{N}$ da planta, diante disso, é considerado um método eficiente para a avaliação do estado nutricional das plantas.

Com relação à característica massa de cem grãos (Tabela 3), pode-se observar que, no ambiente de alto $\mathrm{N}$, a cultivar que apresentou maior massa específica de grãos foi BRS - Aroma. Já no ambiente de baixo N, a cultivar BRS - Bonança

Tabela 3. Média das características massa de cem grãos (MCG) e produtividade de grãos (PROD), sob alta e baixa dose de $\mathrm{N}\left(120 \mathrm{~kg}\right.$ ha ${ }^{-1}$ e $20 \mathrm{~kg}$ ha ${ }^{-1}$, respectivamente), para cultivares de arroz de terras altas na região sul do Estado do Tocantins, Gurupi, Tocantins, safra 2011/2012.

\begin{tabular}{|c|c|c|c|c|c|c|}
\hline \multirow{2}{*}{ Cultivar } & \multicolumn{3}{|c|}{ MCG (g) } & \multicolumn{3}{|c|}{ PROD $\left(\mathrm{kg} \mathrm{ha}^{-1}\right)$} \\
\hline & Alto $\mathbf{N}$ & Baixo N & Média & Alto $N$ & Baixo N & Média \\
\hline BRS-Sertaneja & $1,74 \mathrm{dA}$ & $1,86 \mathrm{bA}$ & 1,81 & $552,77 \mathrm{bA}$ & $520,82 \mathrm{aA}$ & 536,80 \\
\hline BRS-Primavera & $5,63 \mathrm{bA}$ & $1,30 \mathrm{bB}$ & 3,46 & $1558,33 \mathrm{aA}$ & $338,88 \mathrm{aB}$ & 948,61 \\
\hline BRS-Bonança & $1,94 \mathrm{dA}$ & $2,55 \mathrm{aA}$ & 2,24 & $698,60 \mathrm{bA}$ & $508,33 \mathrm{aA}$ & 603,46 \\
\hline BRSMG-Conai & $2,01 \mathrm{dA}$ & $2,47 \mathrm{aA}$ & 2,24 & $319,43 \mathrm{bA}$ & $297,91 \mathrm{aA}$ & 308,67 \\
\hline BRS-Aroma & $8,02 \mathrm{aA}$ & $1,41 \mathrm{bB}$ & 4,71 & $1677,77 \mathrm{aA}$ & $286,10 \mathrm{aB}$ & 981,94 \\
\hline BRS-Monarca & $3,73 \mathrm{cA}$ & $2,20 \mathrm{aB}$ & 2,97 & $695,48 \mathrm{bA}$ & $303,46 \mathrm{aA}$ & 499,47 \\
\hline BRS-Pepita & $2,38 \mathrm{dA}$ & $1,55 \mathrm{bB}$ & 1,96 & $811,80 \mathrm{bA}$ & $278,46 \mathrm{aB}$ & 545,13 \\
\hline BRSGO-Bolinha & $1,43 \mathrm{dA}$ & $1,42 \mathrm{bA}$ & 1,42 & $541,66 \mathrm{bA}$ & $311,80 \mathrm{aA}$ & 426,73 \\
\hline Japonês & $1,49 \mathrm{dA}$ & $1,44 \mathrm{bA}$ & 1,46 & $355,55 \mathrm{bA}$ & $295,13 \mathrm{aA}$ & 325,34 \\
\hline Serra Dourada & $1,81 \mathrm{dA}$ & $1,36 \mathrm{bA}$ & 1,59 & $1279,85 \mathrm{aA}$ & $449,99 \mathrm{aB}$ & 864,92 \\
\hline Média Geral & 3,02 & 1,75 & - & 849,12 & 359,09 & - \\
\hline $\mathrm{CV}(\%)$ & \multicolumn{2}{|c|}{22,57} & & \multicolumn{2}{|c|}{46,31} & \\
\hline
\end{tabular}

Médias seguidas de mesma letra minúscula nas colunas não diferem entre si pelo teste Scott - knott, e de mesma letra maiúscula nas linhas não diferem entre si pelo teste Tukey, a $5 \%$ de probabilidade.

Tabela 4. Média das características relação índice de clorofila $a$ e $b(C l a / C l b)$ e clorofila total (CT), sob alta e baixa dose de $\mathrm{N}_{(120} \mathrm{kg} \mathrm{C}^{-1}$ e $20 \mathrm{~kg}$ ha ${ }^{-1}$, respectivamente), para cultivares de arroz de terras altas na região sul do Estado do Tocantins, Gurupi, Tocantins, safra $2011 / 2012$.

\begin{tabular}{|c|c|c|c|c|c|c|}
\hline \multirow{2}{*}{ Cultivar } & \multicolumn{3}{|c|}{$C l a / C l b(\mathrm{ICF})$} & \multicolumn{3}{|c|}{ CT (ICF) } \\
\hline & Alto N & Baixo N & Média & Alto $N$ & Baixo N & Média \\
\hline BRS-Sertaneja & $3,52 \mathrm{aA}$ & $3,34 \mathrm{aA}$ & 3,43 & $41,89 \mathrm{dA}$ & $40,92 \mathrm{bA}$ & 41,40 \\
\hline BRS-Primavera & $2,46 \mathrm{~dB}$ & $3,09 \mathrm{bA}$ & 2,77 & $53,64 \mathrm{aA}$ & $47,48 \mathrm{aB}$ & 50,56 \\
\hline BRS-Bonança & $2,46 \mathrm{~dB}$ & $2,88 \mathrm{bA}$ & 2,67 & $54,02 \mathrm{aA}$ & $48,66 \mathrm{aB}$ & 51,34 \\
\hline BRSMG-Conai & $2,69 \mathrm{~dB}$ & $3,27 \mathrm{aA}$ & 2,98 & $50,08 \mathrm{bA}$ & $45,55 \mathrm{aB}$ & 47,82 \\
\hline BRS-Aroma & $2,87 \mathrm{cB}$ & $3,50 \mathrm{aA}$ & 3,18 & $48,03 \mathrm{cA}$ & $42,36 \mathrm{bB}$ & 45,20 \\
\hline BRS-Monarca & $2,81 \mathrm{cB}$ & $3,54 \mathrm{aA}$ & 3,17 & $49,34 \mathrm{bA}$ & $43,70 \mathrm{bB}$ & 46,52 \\
\hline BRS-Pepita & $2,66 \mathrm{~dB}$ & $3,52 \mathrm{aA}$ & 3,09 & $51,93 \mathrm{aA}$ & $44,01 \mathrm{bB}$ & 47,97 \\
\hline BRSGO-Bolinha & $3,05 \mathrm{bA}$ & $3,09 \mathrm{bA}$ & 3,07 & $47,86 \mathrm{cA}$ & $45,03 \mathrm{bA}$ & 46,44 \\
\hline Japonês & $3,16 \mathrm{bA}$ & $2,90 \mathrm{bA}$ & 3,03 & $46,27 \mathrm{cA}$ & $47,04 \mathrm{aA}$ & 46,65 \\
\hline Serra Dourada & $2,94 \mathrm{cB}$ & $3,56 \mathrm{aA}$ & 3,25 & $47,57 \mathrm{cA}$ & $44,53 \mathrm{bB}$ & 46,05 \\
\hline Média & 2,86 & 3,27 & - & 49,06 & 44,93 & - \\
\hline $\mathrm{CV}(\%)$ & \multicolumn{2}{|c|}{6,82} & & \multicolumn{2}{|c|}{4,57} & \\
\hline
\end{tabular}

Médias seguidas de mesma letra minúscula nas colunas não diferem entre si pelo teste Scott - knott, e de mesma letra maiúscula nas linhas não diferem entre si pelo teste Tukey, a $5 \%$ de probabilidade. 
apresentou maior massa específica de grãos, sem, porém, diferir das cultivares BRSMG - Conai e BRS - Monarca. Observou-se ainda que o acréscimo de $\mathrm{N}$ não resultou necessariamente em aumento na massa específica de grãos, ou seja, apenas quatro das cultivares avaliadas aumentaram sua massa de sementes com acréscimo do adubo (BRS - Primavera, BRS - Aroma, BRS - Monarca e BRS - Pepita). Resultados semelhantes foram encontrados por Kischel et al. (2011).

Quanto a produtividades de grãos, no ambiente de alto N, as maiores médias foram obtidas pelas cultivares BRS - Aroma, BRS - Primavera e Serra Dourada (Tabela 3). No ambiente de baixo $\mathrm{N}$, não foi detectada diferença significativa entre as cultivares. As produtividades obtidas no experimento ficaram abaixo da média do Estado do Tocantins, que foi de $1.682 \mathrm{~kg} \mathrm{ha}^{-1}$ na safra 2009/2010 (TOCANTINS, 2012). As baixas produtividades ocorreram, sobretudo, pelo estresse hídrico ocorrido a partir da fase de diferenciação dos primórdios florais, prejudicando também a fase de emissão das panículas, fato esse que resultou em panículas mal formadas e com alta esterilidade das espiguetas (Figura 1). De acordo com Heinemann (2010), o estresse hídrico a partir de dez dias antes do período de florescimento induz a cultura do arroz de terras altas a perdas superiores a $60 \%$ da produtividade, sendo crítico na fase de enchimento de grãos.

As cultivares BRS - Aroma e Serra Dourada destacaram-se pelo fato de apresentar maior perfilhamento no período vegetativo e, consequentemente, maior número de panículas $/ \mathrm{m}^{2}$. A cultivar BRS - Primavera também se destacou, por apresentar maiores índices de clorofila (Tabela 4). Cancellier et al. (2011) encontraram resultados semelhantes para a cultivar BRS - Primavera em ambientes de alto e baixo N, na safra 2009/2010.

De acordo com a metodologia proposta por Fageria e Kluthcouski (1980), foram classificadas como eficientes no uso de nitrogênio as cultivares BRS - Sertaneja, BRS - Bonança e Serra Dourada, conforme evidenciado no primeiro e no quarto quadrantes da Figura 2. Na medida em que obtiveram as maiores produtividades em ambientes de baixo N, são consideradas cultivares adaptadas a condição de estresse nutricional de $\mathrm{N}$, portanto, são recomendadas para pequenos

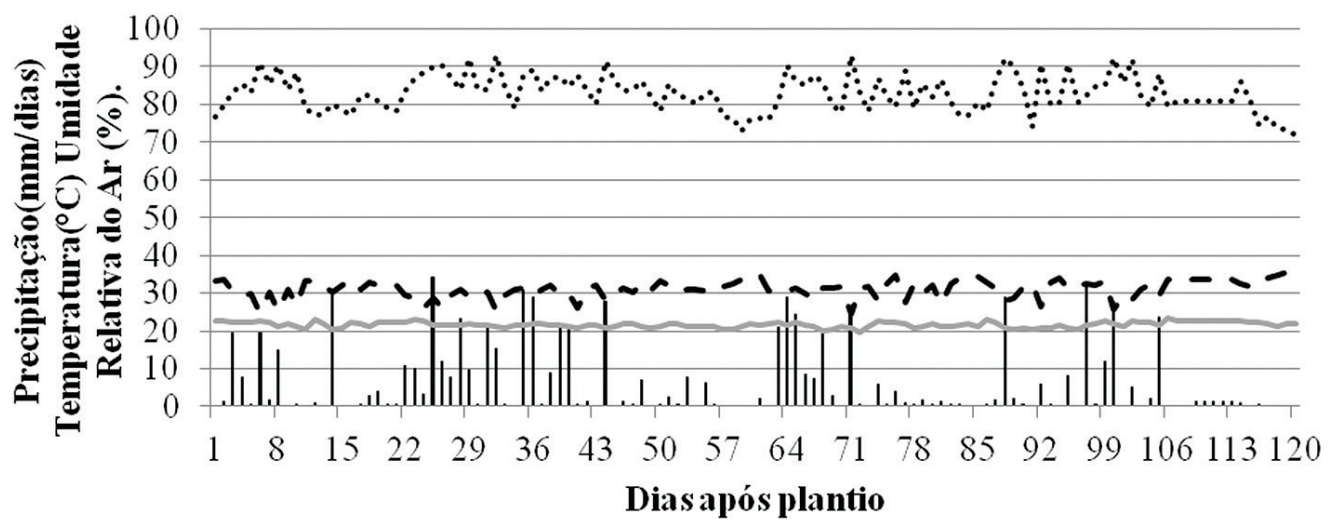

P $(\mathrm{mm} / \mathrm{dia}) \quad-$ TMáx — TMín $\cdots . . . . \mathrm{UR}(\%)$

Figura 1. Precipitação diária, temperatura máxima, temperatura mínima e umidade relativa do ar a partir da data de plantio até a colheita, Gurupi-TO, safra $2011 / 2012$.

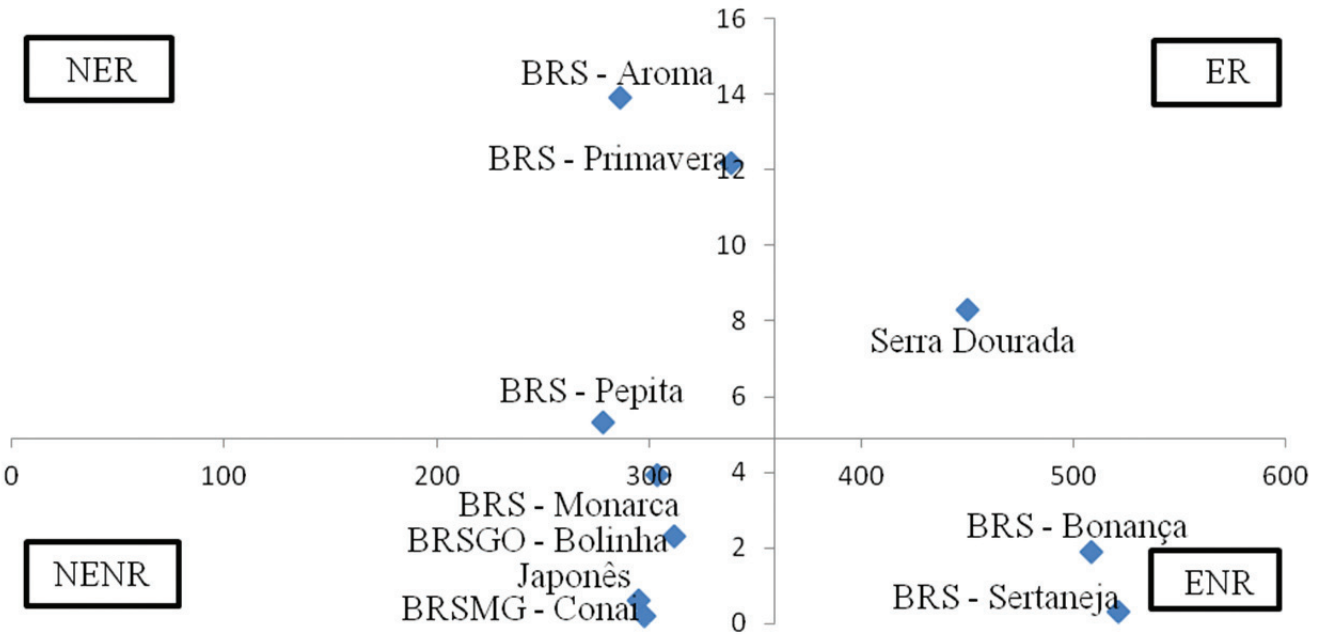

Figura 2. Eficiência no uso e na resposta à aplicação de nitrogênio em cultivares de arroz, pela metodologia de Fageria e Kluthcouski (1980). ER = Eficientes e responsivas; NER = Não eficientes e responsivas; NENR = Não eficientes e não responsivas; ENR = Eficientes e não responsivas. 
produtores que dispõem de pouca tecnologia e recursos financeiros para produzir. Cancellier et al. (2011) obtiveram o mesmo resultado para a cultivar BRS - Bonança na safra 2009/2010.

Quanto à resposta à aplicação de nitrogênio, as cultivares BRS - Aroma, BRS - Primavera, BRS - Pepita e Serra Dourada apresentaram os maiores índices de resposta e são encontradas no primeiro e segundo quadrantes da Figura 2. Estas cultivares apresentam valores de índices de resposta acima de cinco, significando que, a cada quilograma de nitrogênio adicionado, há um aumento de $5 \mathrm{~kg}$ de grãos. Essas cultivares que apresentaram altos índices de resposta são mais indicadas para produtores que utilizam um maior investimento na adubação.

Portanto, a cultivar considerada eficiente e responsiva à aplicação de nitrogênio é a Serra Dourada, assim, é considerada superior às demais, podendo ser indicada para cultivo tanto com alta ou baixa adubação nitrogenada, pois propicia retorno econômico favorável para os dois ambientes (FAGERIA; SANTOS; CUTRIM, 2007). A cultivar Serra Dourada aumentou sua produtividade em $8 \mathrm{~kg} \mathrm{ha}^{-1}$ a cada $\mathrm{kg}$ de nitrogênio adicionado, mas ainda assim produziu abaixo da média para o Estado do Tocantins, que é de $3.686 \mathrm{~kg} \mathrm{ha}^{-1}$ (COMPANHIA..., 2012).

As cultivares BRS - Pepita, BRS - Primavera e BRS - Aroma foram classificadas como não eficientes e responsivas, pois produziram abaixo da média no ambiente de baixo nitrogênio e também apresentaram índices de resposta acima da média, apresentando, para cada quilograma de nitrogênio adicionado, um aumento de 5, $12 \mathrm{e} 13 \mathrm{~kg} \mathrm{ha}^{-1}$, respectivamente, enquadrando-se no segundo quadrante da Figura 2. Essas cultivares são indicadas aos grandes produtores, pois estes investem em tecnologia visando ao aumento da produtividade.

As cultivares classificadas como não eficientes e não responsivas foram BRSMG - Conai, BRS - Monarca, BRSGO - Bolinha e Japonês, que apresentaram produção abaixo da média nos dois ambientes de N. De acordo com essa classificação, essas cultivares não são recomendadas para o cultivo em campo, pois são cultivares que não produzem satisfatoriamente em estresse mineral e nem respondem à adubação nitrogenada.

Foram classificadas como eficientes e não responsivas, as cultivares BRS - Sertaneja e BRS - Bonança. Encontrando-se no quarto quadrante da Figura 2, essas cultivares apresentam boa eficiência na utilização do nitrogênio, mas não respondem ao incremento de nutriente no solo, portanto, são recomendadas aos pequenos produtores, que utilizam baixo investimento em adubação nitrogenada. Cancellier et al. (2011) obtiveram o mesmo resultado para a cultivar BRS - Bonança na safra 2009/2010.

\section{Conclusões}

A cultivar Serra Dourada foi considerada eficiente e responsiva à adubação de $\mathrm{N}$, sendo recomendada para o cultivo em qualquer nível de adubação nitrogenada, na região sul do Estado do Tocantins.
$\mathrm{O}$ ambiente de alto nitrogênio proporcionou um maior número de panículas $/ \mathrm{m}^{2}$ para as cultivares BRSMG - Conai, BRS - Pepita, BRSGO - Bolinha, Japonês e Serra Dourada, e maior massa de cem grãos para as cultivares BRS - Primavera, BRS - Aroma, BRS - Monarca e BRS - Pepita, além de também resultar em uma maior altura de plantas e maior teor de clorofila $a$.

\section{Referências}

BARBIERI JUNIOR, E. Características estruturais, teores de clorofila e suas relações com o nitrogênio foliar e a biomassa em capim-Tifton 85. 2009. 64 f. Dissertação (Mestrado em Zootecnia)Universidade Federal Rural do Rio de Janeiro, Seropédica, 2009.

BARBOSA FILHO, M. P. Nutrição e adubação do arroz: sequeiro e irrigado. Piracicaba: Potafos, 1987. 129 p. (Boletim Técnico, n. 9).

BLUM, A. Plant breeding for stress environments. Boca Raton: CRC Press, 1988. 232 p.

CANCELLIER, E. L. et al. Eficiência agronômica no uso de nitrogênio mineral por cultivares de arroz de terras altas. Revista Brasileira de Ciências Agrárias, Recife, v. 6, n. 4, p. 650-656, 2011. http:// dx.doi.org/10.5039/agraria.v6i4a1420

CASTRO NETO, M. D. Resistência genética de uma coleção nuclear e adubação com silício associado com nitrogênio no manejo de arroz no Sul do Estado do Tocantins. 2009. 66 f. Dissertação (Mestrado em Produção Vegetal)-Universidade Federal do Tocantins, Gurupi, 2009.

COMPANHIA NACIONAL DE ABASTECIMENTO - CONAB. Acompanhamento da safra brasileira: grãos safra 2011/2012, oitavo levantamento, maio/2012. Brasília: Conab, 2012. Disponível em: <http://www.conab.gov.br/OlalaCMS/uploads/ arquivos/12_05_10_08_49_52_boletim_maio_2012.pdf>. Acesso em: 20 maio 2012.

FAGERIA, N. K.; KLUTHCOUSKI, J. Metodologia para avaliação de cultivares de arroz e feijão para condições adversas de solo. Brasília: Embrapa/CNPAF, 1980. 22 p. (Circular Técnica, n. 8).

FAGERIA, N. K.; SANTOS, A. B.; CUTRIM, V. A. Eficiência de uso de nitrogênio por genótipos de arroz irrigado. Santo Antônio de Goiás: Embrapa Arroz e Feijão, 2007. 3 p. (Comunicado Técnico, n. 135).

FAGERIA, N. K.; BALIGAR, V. C.; JONES, C. A. Growth and mineral nutrition of field crops. 2. ed. New York: Marcel Dekker, 1997. 624 p.

FAGERIA, N. K.; BALIGAR, V. C.; CLARK, R. B. Physiology of crop production. New York: Haworth Press, 2006. 345 p.

FAGERIA, N. K.; STONE, L. F. Manejo do nitrogênio. In: FAGERIA, N. K.; STONE, L. F.; SANTOS, A. B. dos. (Eds.) Manejo da fertilidade do solo para o arroz irrigado. Santo Antônio de Goiás: Embrapa Arroz e Feijão, 2003. p. 51-94.

FAGERIA, N. K.; SLATON, N. A.; BALIGAR, V. C. Nutrient management for improving lowland rice productivity and sustainability. Advances in Agronomy, New York, v. 80, p. $63-$ 152, 2003. http://dx.doi.org/10.1016/S0065-2113(03)80003-2

FALKER AUTOMAÇÃO AGRÍCOLA. Medidor eletrônico do teor de clorofila ClorofiLOG 1030. Porto Alegre, 2008. p. 33.

FERREIRA, D. F. Sisvar: a computer statistical analysis system. Ciência e Agrotecnologia, Lavras, v. 35, n. 6, p. 1039-1042, 2011.

FERRAZ JUNIOR, A. S. L. et al. Eficiência do uso de nitrogênio para produção de grão e proteína por cultivares de arroz. Pesquisa Agropecuária Brasileira, Brasília, v. 32, n. 4, p. 435-442, 1997. 
FIDELIS, R. R.; MIRANDA, G. V.; FALUBA, J. S. Capacidade de combinação de populações de milho tropicais sob estresse de baixo nitrogênio. Bioscience Journal, Uberlândia, v. 26, n. 3, p. 358-366, 2010.

HEINEMANN, A. B. Caracterização dos padrões de estresse hídrico para a cultura do arroz (ciclo curto e médio) no estado de Goiás e suas conseqüências para o melhoramento genético. Ciência e Agrotecnologia, Lavras, v. 34, n. 1, p. 29-36, 2010.

KISCHEL, E. et al. Efeito do nitrogênio em genótipos de arroz cultivados em várzea úmida do Estado do Tocantins. Revista Ceres, Viçosa, v. 58, n. 1, p. 84-89, 2011.

SILVA, L. S. et al. Leitura crítica do clorofilômetro para manejo da adubação nitrogenada na cultura do arroz irrigado por alagamento.
Revista Brasileira Agrociência, Pelotas, v. 14, n. 4-4, p. 125 127, 2008.

SILVA, E. A. et al. Avaliação de cultivares de arroz de Terras Altas sob condições de sequeiro em Cassilândia, MS. Ciência e Agrotecnologia, Lavras, v. 33, n. 1, p. 298-304, 2009.

STRECK, N. A. et al. Avaliação de resposta ao fotoperíodo em genótipos de arroz irrigado. Bragantia, Campinas, v. 65, n. 4, p. 533 541, 2006. http://dx.doi.org/10.1590/S0006-87052006000400001

TAIZ, L.; ZEIGER, E. Fisiologia vegetal. 3. ed. Porto Alegre: Artmed, 2004. $721 \mathrm{p}$.

TOCANTINS. Secretaria da Agricultura, Pecuária e Abastecimento - SEAGRO. Evolução da produção do arroz. Disponível em: <http://central2.to.gov.br/arquivo/14/100.01>. Acesso em: 10 jun. 2012. 